\title{
ARTICLE
}

Received 23 Jan 2015 | Accepted 31 Mar 2015 | Published 11 May 2015 DOl: 10.1038/ncomms8077

\section{Absence of surrogate light chain results in spontaneous autoreactive germinal centres expanding $V_{H} 81 X$-expressing $B$ cells}

Ola Grimsholm ${ }^{1, \star}$, Weicheng Ren ${ }^{1, \star}$, Angelina I. Bernardi ${ }^{1}$, Haixia Chen ${ }^{1}$, Giljun Park ${ }^{1}$, Alessandro Camponeschi ${ }^{1}$,

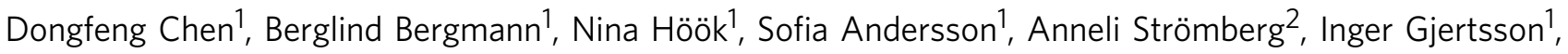
Susanna Cardell ${ }^{2}$, Ulf Yrlid², Alessandra De Riva ${ }^{3} \&$ Inga-Lill Mårtensson ${ }^{1}$

Random recombination of antibody heavy- and light-chain genes results in a diverse B-cell receptor $(B C R)$ repertoire including self-reactive $B C R s$. However, tolerance mechanisms that prevent the development of self-reactive $B$ cells remain incompletely understood. The absence of the surrogate light chain, which assembles with antibody heavy chain forming a pre-BCR, leads to production of antinuclear antibodies (ANAs). Here we show that the naive follicular B-cell pool is enriched for cells expressing prototypic ANA heavy chains in these mice in a non-autoimmune background with a broad antibody repertoire. This results in the spontaneous formation of T-cell-dependent germinal centres that are enriched with B cells expressing prototypic ANA heavy chains. However, peripheral tolerance appears maintained by selection thresholds on cells entering the memory B-cell and plasma cell pools, as exemplified by the exclusion of cells expressing the intrinsically self-reactive $V_{H} 81 X$ from both pools.

\footnotetext{
${ }^{1}$ Department of Rheumatology and Inflammation Research, University of Gothenburg, PO Box 480, Gothenburg SE-405 30, Sweden. ${ }^{2}$ Department of Microbiology and Immunology, University of Gothenburg, PO Box 435, Gothenburg SE-405 30, Sweden. ${ }^{3}$ CIMR Medicine, PO Box 139 , Wellcome Trust/MRC Building, Cambridge Biomedical Campus, Cambridge CB2 OXY, UK. * These authors contributed equally to this work. Correspondence and requests for materials should be addressed to I.-L.M.(email: lill.martensson@rheuma.gu.se).
} 
A utoimmune diseases, for example, systemic lupus erythematosus (SLE) and rheumatoid arthritis (RA), have been associated with defective B-cell tolerance, mechanisms that in healthy individuals prevent the development of selfreactive naive peripheral $\mathrm{B}$ cells $\mathrm{s}^{1-3}$. A hallmark of these diseases is the production of autoantibodies ${ }^{4,5}$, for instance, anti-DNA and antinuclear antibodies (ANAs) in SLE, which can be detected long before disease onset ${ }^{6,7}$. Autoantibodies are produced under both T-cell-independent and -dependent (Td) conditions. The latter are of particular concern as they involve germinal centre (GC) formation, secondary structures that support B-cell clonal expansion, alter antibody effector function and antigen affinity, and result in immunological memory that can last for a lifetime $^{8-12}$. In autoimmune diseases, and mouse models thereof, GCs develop spontaneously ${ }^{13,14}$, suggesting additional levels of self-tolerance acting at GCs that are defective in these diseases ${ }^{15}$.

Random recombination of $V(D) J$ gene segments, encoding antibody heavy and light chain variable regions, results in a highly diverse primary repertoire of B-cell receptors (BCRs), that is, membrane-bound antibodies. As the recombination also results in those that are self-reactive, several mechanisms are in place to eliminate self-reactivity from the naive B-cell pool. At the pro-Bcell stage early in B-cell development $V D J_{H}$ recombination leads to expression of an antibody $\mu$-heavy $(\mu \mathrm{H})$ chain. This assembles with the invariant surrogate light (SL) chain, encoded by VpreB and $\lambda 5$, and the signalling molecules $\operatorname{Ig} \alpha / \beta$ forming $a$ pre-BCR ${ }^{16,17}$, where association with the SL chain serves as a quality control of $\mu \mathrm{H}$ chains. A dysfunctional $\mu \mathrm{H}$ chain results in a block in B-cell development at the pro-B-cell stage, whereas a dysfunctional SL chain allows these cells to transit to the pre-B-cell stage, although pre-B-cell numbers are greatly reduced $^{16}$.

The $\mathrm{H}$ chain complementarity determining region 3 (H-CDR3), encoded by the $V_{H} D J_{H}$ junction, is the most variable of the three CDRs, and plays a central role in recognition of both antigen and autoantigen ${ }^{18-23}$. A characteristic of a majority of anti-DNA and ANAs is a H-CDR3 with one, or more, basic amino acid (aa) residues (ANA H-CDR3) that is critical to antigen binding ${ }^{15,21}$. Also the non-Ig portion of $\lambda 5$ ( $\lambda 5$-tail) contains basic amino acid residues that are critical to pre-BCR signalling ${ }^{24-27}$. Moreover, some of the pre-B cells that develop in both mice and humans with a dysfunctional SL chain ${ }^{28,29}$ express $\mu \mathrm{H}$ chains characterized by a prototypic ANA H-CDR3 (refs 24,25). Nevertheless, as the pre-B cells in mice lacking SL chain $\left(S L C^{-/}\right)$proceed in development, they encounter strong selection pressure as both immature and transitional B cells ${ }^{30}$. Despite this B-cell tolerance is seemingly defective, as serum levels of, for example, anti-double-stranded DNA and ANAs are elevated in these mice ${ }^{28}$.

SL chain is only expressed in early B-cell lineage cells, and hence its absence represents a monogenic and B-cell intrinsic defect. The $S L C^{-/-}$mouse is thus a unique model in which to investigate B-cell tolerance mechanisms without the complexity of multiple genetic loci being involved, as in multigenic autoimmune diseases. Moreover, as they express a diverse antibody repertoire and on a lupus-resistant background, this model allows the changes in the BCR repertoire imposed by tolerance mechanisms to be uncovered not possible with monoclonal Ig transgenic mice. Using the $S L C^{-/-}$ mouse model, we have investigated whether self-reactive naive peripheral $B$ cells develop and the consequences of this. We show that the pool of naive B cells in $S L C^{-1-}$ mice is indeed enriched for autoreactivity, and that this in itself is sufficient to initiate spontaneous formation of persistent Td GCs. However, peripheral tolerance appears maintained by selection thresholds on GC B cells entering the memory B-cell and plasma cell pools.

\section{Results}

B cells with prototypic ANA H-CDR3 enriched in $S L C^{-/-}$mice. To investigate whether self-reactive naive follicular (FO) B cells develop in $S L C^{-/-}$mice, we used a prototypic ANA H-CDR3 (1 or $\geq 2$ arginine and/or lysine) as a marker. Assessing $\mu \mathrm{H}$ chains expressed during B-cell development, we observed a decrease in proportions of cells with a prototypic ANA H-CDR3 comparing pro-B with FO B cells from control mice $(P<0.0001$; $\chi^{2}$-test; Fig. 1a). By contrast, in $S L C^{-/-}$mice, an enrichment was

a

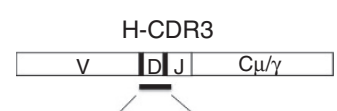
CARNYGSRREGYFDVW

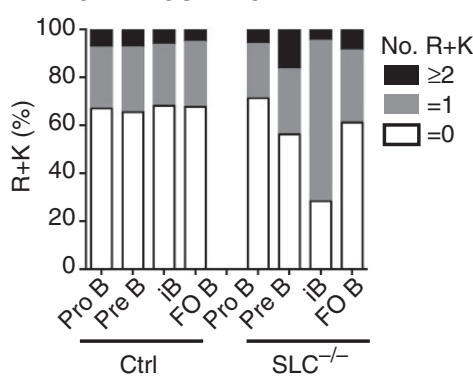

b

C

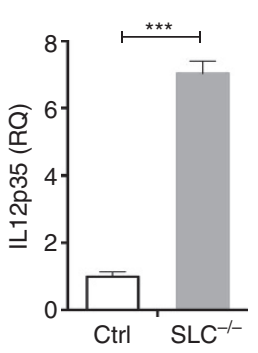

d
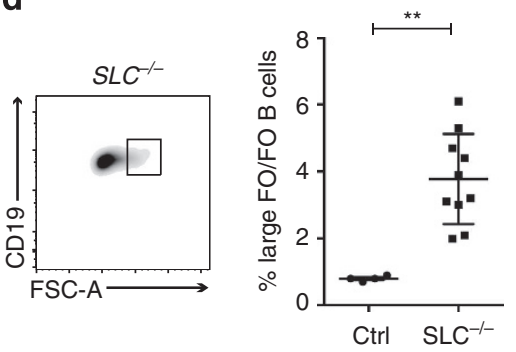

e

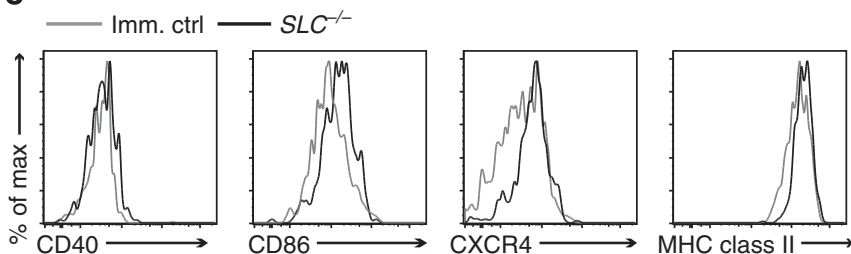

Figure 1 | FO B cells with prototypic ANA H-CDR3 are enriched in SLC ${ }^{-/}$mice, and includes a subset of large, activated cells. (a)

Sequence analysis of $\mathrm{Ig} \mu \mathrm{H}$ chains expressed in pro-B (14610; 12906), pre-B (12870; 1950), immature B (35516; 9152) and FO B (29554; 564) cells in control (Ctrl) and SLC ${ }^{-/-}$mice, showing proportions of $\mathrm{H}-\mathrm{CDR} 3$ sequences with 0,1 or $\geq 2$ arginine $(R)$ and/or lysine $(K)$ residues. $(\mathbf{b}, \mathbf{d}, \mathbf{e})$ Flow cytometry analysis of spleen cells. (b) Expression of indicated parameters on FO B cells from Ctrl and SLC ${ }^{-/-}$mice. (c) QPCR analysis of IL12p35 in FO B cells from indicated mice. The mRNA levels were normalized to $\beta$-actin. Levels in $\mathrm{FO} B$ cells from $\mathrm{Ctrl}$ mice were set to 1 . (d) Gating on FO B cells from $\mathrm{SLC}^{-/}$- mice plot shows forward scatter (FSC) versus CD19, indicating a subset of cells that is larger in cellular size. Graph shows \% large cells of total FO B cells in Ctrl and SLC ${ }^{-/}$mice. (e) Histograms show expression of indicated markers on the subset of larger FO B cells in SLC ${ }^{-/-}$and SRBC-immunized (Imm.) ctrl mice. Data in $\mathbf{a}$ are from a pool of six mice. Numbers in parenthesis indicate unique sequences from ctrl and $S L C^{-/-}$mice, respectively. Data (b-e) are representative or pooled (c) from at least two independent experiments. Each symbol represents one mouse. Error bars represent s.e.m. $P$ values were determined using a two-tailed $t$-test. ${ }^{\star \star} P<0.01,{ }^{\star \star \star} P<0.001$. 
evident in the pre-B compared with the pro-B cells $(P<0.0001$; $\chi^{2}$-test), and in the immature $\mathrm{B}$ cells the proportions were even higher $\left(P<0.0001 ; \chi^{2}\right.$-test), where a majority of H-CDR3 contained one arginine/lysine. In the FO B cells, a reduction was observed compared with the immature $\mathrm{B}$ (and pre-B) cells $\left(P<0.0001 ; \chi^{2}\right.$-test $)$, however, the proportions of both those with 1 and $\geq 2$ arginine and/or lysine were still higher in the FO B cells from $S L C^{-/-}$mice than in controls $(P<0.0001$; $\chi^{2}$-test). Thus, cells that express $\mu \mathrm{H}$ chains with a prototypic ANA $\mathrm{H}$-CDR3 are enriched in SLC ${ }^{-/-}$mice among pre-B cells, as well as at later developmental stages, consistent with the notion that the pool of naive FO B cells in $S L C^{-/-}$mice is enriched for autoreactivity.

A subset of pre-GC B cells among the naive FO B-cell pool. Next we investigated whether the apparent lack of tolerance among FO B cells in $S L C^{-/-}$mice was accompanied by a change in phenotype. The FO B cells from these mice were larger in size and the levels of major histocompatibility complex (MHC) class II were higher (Fig. 1b), whereas those of IgM, IgD, CD19, CD40, CD69 and CD23 were not changed to the same extent or not at all (Supplementary Fig. 1a). Although this could indicate a state of activation, the levels of $\mathrm{p}$-Erk or p-Blnk were not elevated (Supplementary Fig. 1b). Microarray analysis of RNA from FO B cells showed that the levels of $\mathrm{Fas}$ and $\mathrm{Cd} 40$, and those of $\mathrm{Ccl} 3$ and Ccl5 (encoding chemokines) were higher in the FO B cells from $S L C^{-/-}$mice than controls (Supplementary Table 1). Most noticeable were the elevated levels of $I L-12 a$, a cytokine that supports differentiation into $\mathrm{T}$ follicular helper $\left(\mathrm{T}_{\mathrm{FH}}\right)$ cells $\mathrm{s}^{31}$, which was confirmed by quantitative PCR (qPCR) of IL12p35 (Fig. 1c). We also noticed that the FO B cells from $S L C^{-/-}$mice could be divided into two subsets based on cellular size (Fig. 1d). The proportion of large cells was increased compared with controls already at an age of 4-5 weeks, and also at this age the larger cells expressed higher levels of CD86 and MHC class II (Supplementary Fig. 2a-c). Together, these data suggest that a subset of the FO B cells in $S L C^{-/-}$mice is activated, and that this involves signalling through the BCR and toll like receptor (TLR) (Ccl3 and Ccl5) pathways ${ }^{32,33}$, as well as interactions with $\mathrm{T}$ cells.

Because of the apparent involvement of $\mathrm{T}$ cells in activating the FO B cells, to generate B cells typical of Td immune responses for comparison, we immunized control mice with sheep red blood cells (SRBCs). One and two weeks post immunization, a subset of larger cells was detected among the splenic FO B cells with higher levels of CD40, CD86, CXCR4 and MHC class II than on the small cells (Supplementary Fig. 3). The size of these large cells in the immunized control mice was similar to that of the larger FO B cells in (unimmunized) $S L C^{-/-}$mice, as were the levels of CD40, CD86, CXCR4 and MHC class II (Fig. 1e). Over the last years, precursors of GC (pre-GC) B cells have been described ${ }^{34}$, which opened the possibility that the large FO B cells in $S L C^{-/-}$ mice represented pre-GC B cells.

Spontaneous formation of GCs. The uncovering of potential pre-GC B cells in $S L C^{-/-}$mice prompted us to investigate whether we could also detect GCs. Analysing splenic cryosections identified $\mathrm{B} 220^{+} \mathrm{GL}^{+}$cells located in B-cell follicles close to the $\mathrm{T}: \mathrm{B}$-cell border in $S L \mathrm{C}^{-/-}$mice but not in control mice (Fig. 2a), and flow cytometry analysis confirmed the presence of a $\mathrm{CD} 19^{+} \mathrm{CD}^{+} 5^{+} \mathrm{GL} 7{ }^{+}$B-cell population in $S L C^{-/-}$mice (Fig. 2b,c). Thus, GCs develop spontaneously in $S L C^{-/-}$mice, a
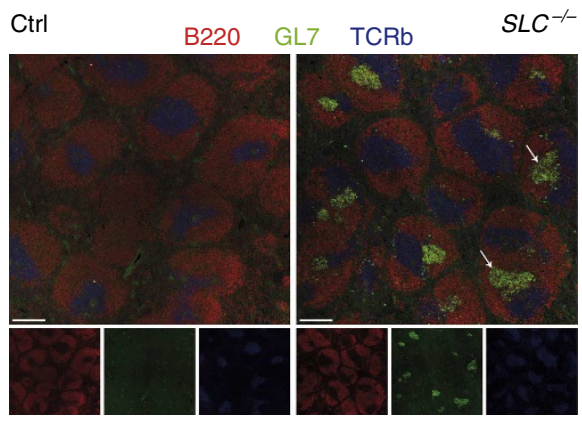

C

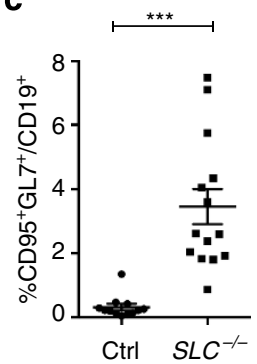

d

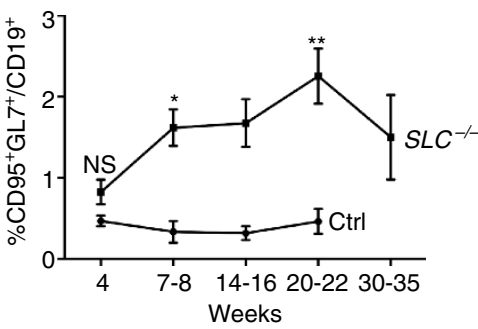

b
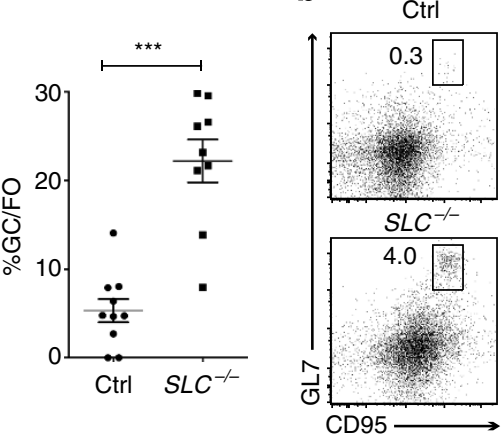

e

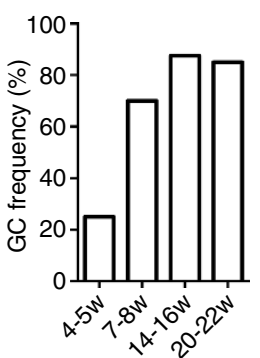

Figure 2 | Spontaneous formation of splenic GCs. (a) Immunofluorescence staining of spleen cryosections from control (Ctrl) and SLC ${ }^{-/-}$mice. GL7 (green), B220 (red) and TCR $\beta$ (blue). Arrows indicate GC structures, $\times 10$ objective; scale bars, $200 \mu \mathrm{m}$. Graph shows \% GCs per follicles (FO, two independent observers). (b-e) Flow cytometry analysis of spleen cells. (b) Dot plots show $\mathrm{CD} 95^{+} \mathrm{GL} 7{ }^{+} \mathrm{GC}$ B cells among CD19+ B cells. (c) Graph shows \% CD95 ${ }^{+} \mathrm{GL7}{ }^{+} \mathrm{GC} \mathrm{B}$ cells among $\mathrm{CD} 19^{+} \mathrm{B}$ cells in Ctrl and SLC ${ }^{-/-}$mice. (d) Graph shows \% CD95 ${ }^{+} \mathrm{GL}^{+}{ }^{+}$cells in $\mathrm{CD} 19^{+} \mathrm{B}$ cells at indicated ages in $\mathrm{Ctrl}$ and $\mathrm{SLC}{ }^{-/-}$mice. (e) Graph shows frequency of mice with $\geq 1.0 \% \mathrm{CD}^{-} 5^{+} \mathrm{GL7}^{+}$cells in $\mathrm{CD}^{+}{ }^{+} \mathrm{B}$ cells at indicated ages in $\mathrm{SLC}{ }^{-/-}$mice. Data in $\mathbf{a}$ and $\mathbf{b}$ are representative, and in $\mathbf{a}$ and $\mathbf{c}-\mathbf{e}$ are pooled from at least two independent experiments. Each symbol represents one mouse. Error bars represent s.e.m. $P$ values were determined using a two-tailed $t$-test. ${ }^{\star} P<0.05 ;{ }^{\star \star} P<0.01 ;{ }^{\star \star \star} P<0.001 ; N S$, not significant; $w$, weeks. 
an unexpected observation, considering that the mice had not been actively immunized. Investigating the kinetics showed that in 4week-old $S L C^{-1-}$ mice, few, if any, GCs were detected by contrast to 7-8-week-old mice when GCs were found in $\sim 70 \%$ of the animals, and by 10-14 weeks nearly all mice presented with GCs (Fig. 2d,e). Their presence also at an age of 30-35 weeks suggested that in $S L C^{-/-}$mice, the GCs persist over long periods of time.

Splenic GCs are present after antibiotics treatment. The spontaneous formation of GCs in $S L C^{-/-}$mice was unexpected, as they had not been actively immunized and the defect is B-cell intrinsic. However, as the FO B cells in these mice were enriched for cells expressing a BCR with a prototypic ANA H-CDR3, we reasoned that a possible trigger for GC formation could have been the gut microbiota, as a germ-free environment has been shown to lead to milder disease in some autoimmune models ${ }^{35}$. To investigate the influence of intestinal microbes, $S L C^{-/-}$mice were placed on broad-spectrum antibiotics from the time of weaning, when GCs had not yet been established (Fig. 2d), in order to deplete of the normal gut microbiota (Fig. 3a). As expected from this treatment ${ }^{36}$, the proportion of GC B cells in Peyer's patches were reduced in $S L C^{-/-}$mice treated with antibiotics (Fig. 3b,c), which was corroborated by a reduction in IgA plasma cells in the intestine and faecal bacterial load (Fig. 3d,e). In the antibiotic, but not untreated, group, the spleen size was much smaller as shown by the reduction in B-cell numbers (Fig. 3f). However, the proportion of splenic GC B cells was not changed (Fig. 3g), which was corroborated by the presence of GC structures and serum IgG ANAs in both groups (Supplementary Tables 2 and 3). It would thus appear that the gut microbiota is not the main trigger of GC formation in $\mathrm{SLC}^{-9-}$ mice.

Skewed ratio of $\mathbf{T}_{\mathbf{F H}}$ to GC $\mathbf{B}$ cells. GC formation and maintenance is controlled by the interplay between different cell types, including follicular dendritic cells (FDCs), $\mathrm{T}_{\mathrm{FH}}$ cells and $\mathrm{B}$ cells ${ }^{37-}$ 42. In $S L C^{-/-}$mice, networks of CD35 ${ }^{+}$FDCs were detected in the GC zone proximal to the B-cell follicle (Fig. 4a); most likely in the light zone (LZ) where B cells would normally encounter FDCtrapped antigens. Assessing the presence of T cells demonstrated that TCR $\beta^{+}$cells were located in the GCs (Fig. 2a), as well as $\mathrm{CD} 4{ }^{+}$cells of which some were Bcl- $6^{+}$(Fig. $4 \mathrm{~b}$ ), the pivotal transcription factor expressed by $\mathrm{T}_{\mathrm{FH}}$ cells. The presence of $\mathrm{T}_{\mathrm{FH}}$ cells in $S L C^{-/-}$mice was confirmed by the enrichment of $\mathrm{CD}^{+}$cells expressing high levels of PD-1 (Fig. 4c,d), whereas number of $\mathrm{CD}^{+} \mathrm{T}$ cells as well as percentage of regulatory $\mathrm{T}$ cells within this pool were similar in $S L C^{-/-}$and control mice (Supplementary Fig. 4a,b). Moreover, CD62L, a cell adhesion molecule that is downregulated upon activation of naive $\mathrm{CD} 4{ }^{+} \mathrm{T}$ cells, was absent on the vast majority of $\mathrm{CD} 4^{+} \mathrm{PD}-1$ hi cells by contrast to most $\mathrm{CD}^{+}$cells (Fig. 4e). Analyses by qPCR confirmed the expression of Bcl6, and demonstrated high levels of

a

Age $0 \quad 3-4 \mathrm{w} \quad$ Antibiotics in drinking water 7-8 w

b

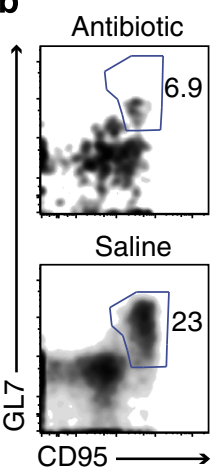

e

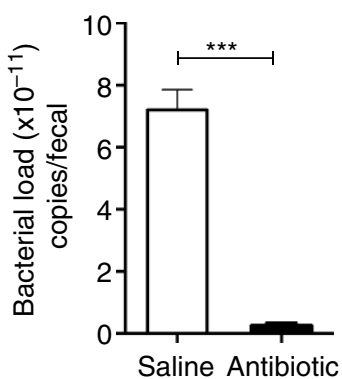

C

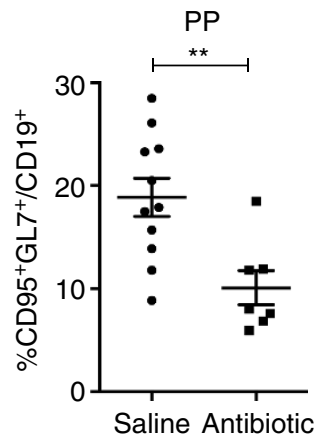

d

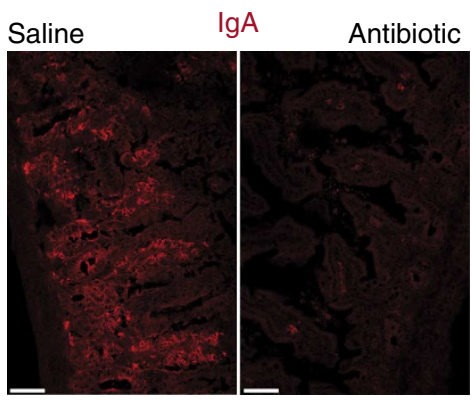

g

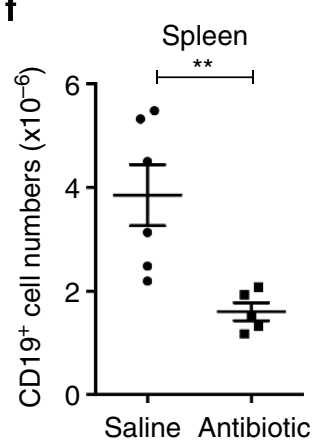

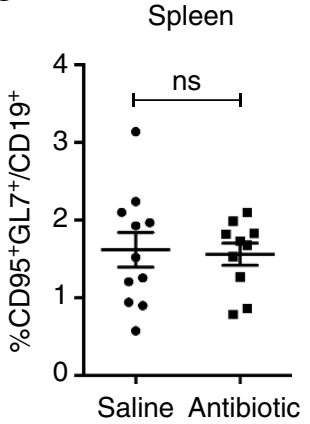

Figure 3 | Gut microbiota is not a main trigger of spontaneous GC formation. (a-g) SLC ${ }^{-/-}$mice were treated with broad-spectrum antibiotics or saline water. (a) Experimental design: antibiotic treatment of $S L C^{-/-}$mice was started at an age of 3-4 weeks (w) and completed 4 weeks later. (b) Dot plots show $\mathrm{CD} 95^{+} \mathrm{GL}^{+}$cells in $\mathrm{CD} 19^{+}$cells from Peyer's patches (PP). (c) Graph shows \% of $\mathrm{CD} 95^{+} \mathrm{GL7}^{+}$cells in $\mathrm{CD} 19^{+}$cells from PP. (d)

Immunofluorescence staining of intestine cryosections with antibodies detecting lgA, $\times 10$ objective; scale bars, $50 \mu \mathrm{m}$. (e) qPCR analysis of total bacterial DNA copy numbers in faeces. (f) Graph shows total splenic CD19 ${ }^{+}$cell numbers. (g) Graph shows \% splenic $\mathrm{CD} 95^{+} \mathrm{GL} 7^{+}$cells among $\mathrm{CD} 19+{ }^{+}$cells. Data are representative from two independent experiments. Each symbol represents one mouse. Error bars represent s.e.m. $P$ values were determined using a two-tailed $t$-test. ${ }^{\star \star} P<0.01,{ }^{\star \star \star} P<0.001 ; N S$, not significant. 
a

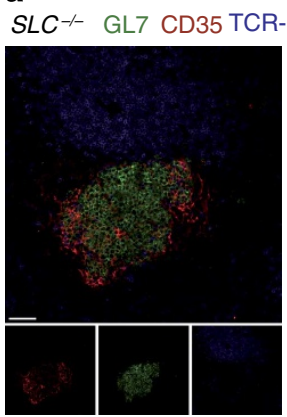

b

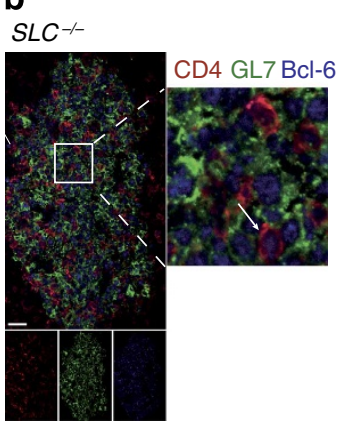

C

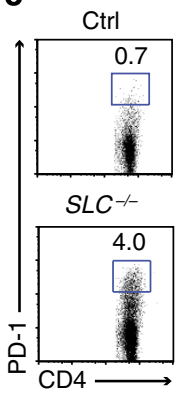

d

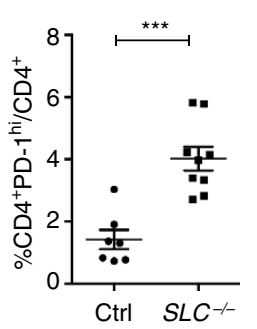

e

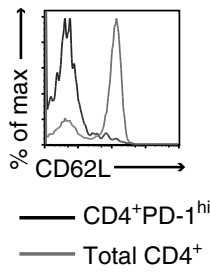

9

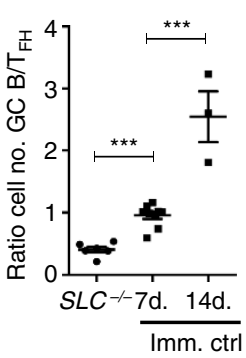

h

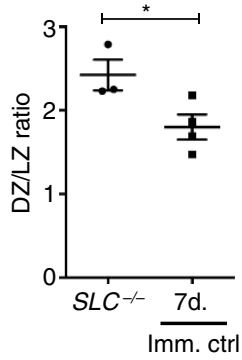

f

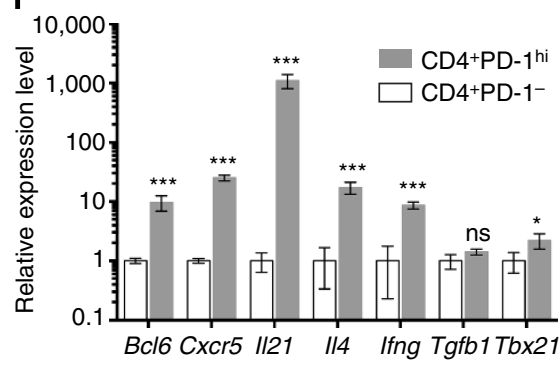

i

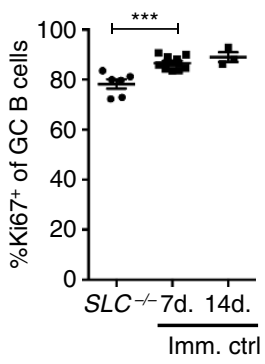

j

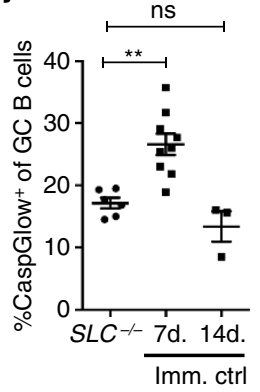

Figure 4 | Skewed ratio of $\mathbf{T}_{\mathbf{F H}}$ :GC B cells. (a,b) Immunofluorescence staining of spleen cryosections from SLC ${ }^{-/-}$mice. GL7 (green). (a) Detection of $\mathrm{CD}^{+}{ }^{+} \mathrm{FDC}$ networks. CD35 (red), TCRß (blue), $\times 25$ objective; scale bar, $50 \mu \mathrm{m}$. (b) Detection of CD4 ${ }^{+} \mathrm{T}_{\mathrm{FH}}$ cells, and those expressing Bcl-6 (arrow) CD4 (red), Bcl-6 (blue), $\times 40$ objective; scale bar, $20 \mu \mathrm{m}$. (c-e,g-j) Flow cytometry analysis of spleen cells. (c) CD4 ${ }^{+}$PD- $1^{\text {hi }} \mathrm{T}_{\mathrm{FH}}$ cells gated on CD4 ${ }^{+}$cells in Ctrl and SLC ${ }^{-/-}$mice. (d) Graph shows percentages CD4 ${ }^{+} \mathrm{PD}-1^{\mathrm{hi}} \mathrm{T}_{\mathrm{FH}}$ cells gated on CD4 ${ }^{+}$cells. (e) Expression of CD62L on CD4 ${ }^{+}$and CD4 ${ }^{+} \mathrm{PD}-1^{\mathrm{hi}}$ T cells from SLC ${ }^{-/-}$mice. (f) QPCR analysis of Bcl6, Cxcr5, II21, II4, Ifng, Tgfb1 and Tbx21 (T-bet) mRNA levels in naive CD4 ${ }^{+}$PD-1 ${ }^{-}$and CD4 ${ }^{+}$PD- $1^{\text {hi }} T^{-}$ cells from SLC ${ }^{-/-}$mice, with $\beta$-actin as internal ctrl. (g) Graph shows ratio of GC B/T $\mathrm{FH}_{\mathrm{FH}}$ cell numbers in SLC ${ }^{-/-}$and SRBC-immunized control (Imm. ctrl) mice. (h) Graph shows DZ/LZ ratio in indicated genotypes. (i) Graph shows \% Ki-67 ${ }^{+}$cells in the CD19 ${ }^{+} \mathrm{CD} 95^{+} \mathrm{GL7}{ }^{+}$gate. (j) Graph shows $\%$ CaspGlow ${ }^{+}$(activated caspases) in the $\mathrm{CD} 19+{ }^{+} \mathrm{CD} 95^{+} \mathrm{GL} 7{ }^{+}$gate. Data are representative from at least two independent experiments except for $(\mathbf{g}, \mathbf{i}, \mathbf{j}$ ) day (d) 14 post immunization, which was only performed once. Data in $\mathbf{d}$ are pooled from three independent experiments. Each symbol represents one mouse. Data in $\mathbf{f}$ are from two independent experiments with at least four mice in each. Error bars represent s.e.m. $P$ values were determined using a twotailed $t$-test. ${ }^{\star} P<0.05,{ }^{\star \star} P<0.01,{ }^{\star \star \star} P<0.001$; NS, not significant.

Cxcr5 in $\mathrm{CD} 4{ }^{+} \mathrm{PD}-1^{\text {hi }}$ compared with $\mathrm{CD} 4^{+} \mathrm{PD}-1^{-}$cells (Fig. 4f). This assay also showed higher levels of Il4, Ifng and Tbx21 (T-bet), as well as a 1,000-fold increase in Il21 mRNA levels in the $\mathrm{CD} 4{ }^{+} \mathrm{PD}-1^{\text {hi }}$ population but unchanged levels of Tgfbl.

As expected, $\mathrm{T}_{\mathrm{FH}}$ cells were also detected in the SRBCimmunized control mice (Fig. 4g). However, as the number of $\mathrm{T}_{\mathrm{FH}}$ but not GC B cells was similar in $S L C^{-/-}$and immunized control mice, the ratio of $\mathrm{T}_{\mathrm{FH}}$ to GC B cells differed (Fig. 4g). In the immunized control mice, the ratio changed such that at 1 week into the response it was 1:1, whereas at 2 weeks there were less $\mathrm{T}_{\mathrm{FH}}$ cells per GC B cells $(1: 2.5)$. By contrast, in $S L C^{-1-}$ mice, the ratio was reversed with more $\mathrm{T}_{\mathrm{FH}}$ cells per GC B cells (2:1), hence fivefold more compared with the SRBC response at 2 weeks. Thus, the cellular composition in the spontaneously developing GCs in $S L C^{-/-}$mice is altered.
Reduced expansion and apoptosis of GC B cells. $\mathrm{T}_{\mathrm{FH}}$ cells are pivotal to GC B-cell dynamics providing signals affecting their expansion, survival and fate ${ }^{37-39,42-44}$. GCs can be divided into dark zone (DZ) and LZ, with B-cell proliferation taking place in the former and selection in the latter, where $T$ cells and FDCs are mainly located. Determining the ratio of DZ:LZ, based on surface expression of CXCR4 and CD86, showed that this was 2.3:1 in $S L C^{-/-}$mice and 1.8:1 in SRBC-immunized control mice (Fig. 4h). The proportion of GC B cells that expressed the proliferation marker $\mathrm{Ki}-67$ was lower in $S L C^{-/-}$mice than in immunized controls, $80 \%$ and $90 \%$, respectively (Fig. 4i). The expression of $\mathrm{Ki}-67$ in $S L C^{-/-}$GCs was confirmed on cryosections (Supplementary Fig. 5a). Staining for active caspases, a marker of cells prone to undergoing apoptosis showed that the proportions in $S L C^{-/-}$mice were about the same as those in immunized control mice at 2 weeks but not at 1 
week (Fig. 4j). Moreover, splenic GC B cells in $S L C^{-/-}$mice expressed Bcl-6 (Fig. 4b and Supplementary Fig. 5b), a transcription factor critical also for GC B cells. Thus, the cellular dynamics in the spontaneously developing GCs in $S L C^{-/-}$mice are altered, resulting in reduced expansion and apoptosis of the GC B cells.

B:T-cell interactions are required for maintenance of pre-GC B cells and GCs. To address whether T cells were required for GC maintenance in $S L C^{-/-}$mice, the CD40:CD40L co-stimulation, necessary for cognate B:T-cell interactions $s^{37-39,45}$, was disrupted by treating the mice with anti-CD40L antibodies (Fig. 5a).
Analyses 6 days after the first injection demonstrated that this treatment completely abolished the GC structures (Fig. 5b and Supplementary Fig. 6a), corroborated by the severe reduction in $\mathrm{CD} 95^{+} \mathrm{GL}^{+}$cells (Supplementary Fig. 6b). This effect was still evident 5 weeks after the initial injection, when GC B cells were still absent and $\mathrm{T}_{\mathrm{FH}}$ cells reduced (Fig. $5 c, \mathrm{~d}$ ). Moreover, the reduction in pre-GC $\mathrm{B}$ cells (Fig. 5e) also demonstrated their dependence on CD40/CD40L co-stimulation. By contrast, the proportions of $\mathrm{FO}, \mathrm{B} 1$ or marginal zone $\mathrm{B}$ cells were not reduced 5 weeks after anti-CD40L antibody treatment (Supplementary Fig. 6c). Thus, the maintenance of pre-GC B cells as well as GCs in $S L C^{-/-}$mice requires B:T-cell interactions.

$\begin{array}{rrrrrr}\text { Day } 0 & 2 & 4 & 6 & 11 & 33 \\ \alpha \text {-CD40L i.v. } \uparrow & \uparrow & \uparrow & + & \uparrow & \uparrow\end{array}$

b

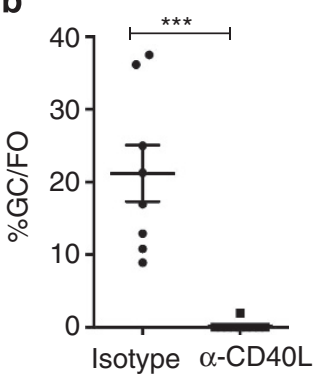

e

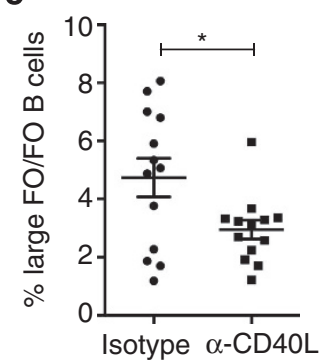

h Isotype

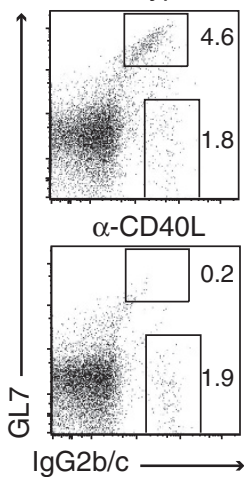

i
C

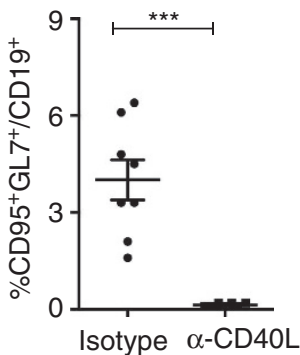

f

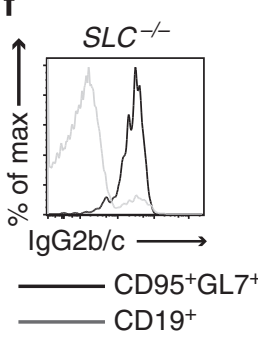

d

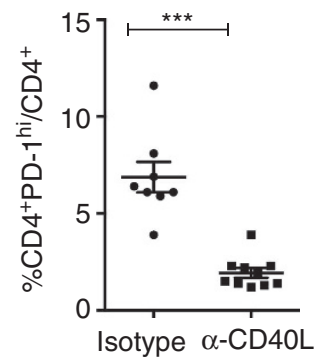

9

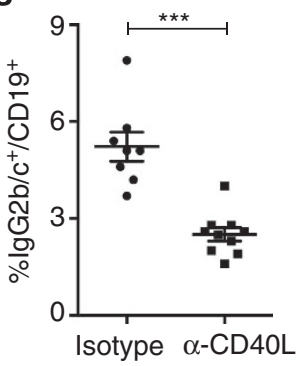

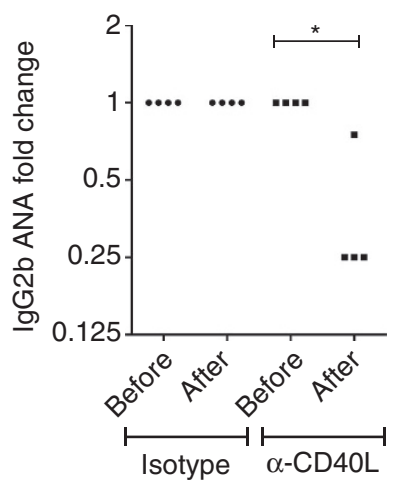

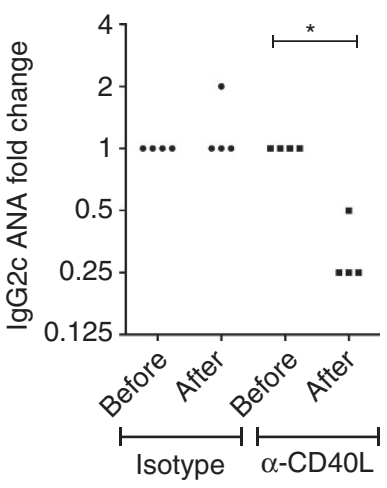

Figure 5 | Td maintenance of GCs and serum IgG2b/c ANAs. (a-e,g-i) SLC ${ }^{-/-}$mice were treated with anti-CD4OL or isotype control antibodies, and killed after 6 days (b) or 5 weeks (c-e,g-i). (a) Experimental setup. (b) Graph shows \% GCs per follicles (FO, two independent observers). (c-h) Flow cytometry analysis of spleen cells. (c) Graph shows \% CD95 ${ }^{+} \mathrm{GL} 7^{+}$cells among CD19+ cells. (d) Graph shows \% CD4 ${ }^{+}$PD - hi $^{\text {hi }}$ cells among $\mathrm{CD} 4{ }^{+}$cells. (e) Graph shows \% large cells of total FO B cells. (f) Expression of cell surface lgG2b/c after gating on GL7+ and CD19+ cells in SLC ${ }^{-} /-$mice. Note that these are untreated. (g) \% lgG2b/c ${ }^{+}$cells among CD19+ cells. (h) Expression of lgG2b/c on $\mathrm{GL}^{+}{ }^{+}$and $\mathrm{GL} 7^{-}$cell populations among $\mathrm{CD} 19^{+}$cells. (i) Graphs show fold change of serum IgG2b and IgG2c ANAs before and after treatment. Data are representative and pooled (b-e,g) from at least two independent experiments. Each symbol represents one mouse. Error bars represent s.e.m. $P$ values were determined using a two-tailed $t$-test. ${ }^{\star} P<0.05$, ${ }^{\star \star \star} P<0.001$; i.v., intravenous; NS, not significant. 
Td production of serum IgG2b and IgG2c ANAs. Our previous work implicated a $\mathrm{CD} 21^{-} 23^{-}$mature B-cell population as the origin of IgG ANA production in $S L C^{-/-}$mice $^{28}$. Here we find that the GC B cells represent a subset of this population; high levels of GL7 were expressed on $20-25 \%$ of this but not on classical B-cell populations (Supplementary Fig. 7a,b). Further analysis confirmed that a subset of the $\mathrm{CD} 21^{-} 23^{-}$population in $S L C^{-1-}$ mice displayed a phenotype typical of GC B cells (Supplementary Fig. 7c). This opened up the possibility that the GC B cells give rise to the plasma cells producing IgG ANAs in $S L C^{-/-}$mice. Consistent with this, the process of class switch recombination was active in the GC B cells; the levels of Aicda, encoding the enzyme pivotal for class switch recombination, and Ig $\gamma 2 b$ and $\gamma 2 c$ sterile transcripts, and $V_{J 558} D J-\gamma 2 b$ and $-\gamma 2 c$ mRNA were all higher than in FO B cells from $S L C^{-1-}$ and control mice (Supplementary Fig. 8a-c). Moreover, the vast majority (90\%) of GC B cells expressed IgG2b/c on their surface (Fig. 5f). We also detected IgG2c serum ANAs (Supplementary Fig. 8d) in addition to the IgG2b ANAs ${ }^{28}$, the former an isotype specific to $\mathrm{Td}$ responses, whereas the latter is produced also under T-cell-independent conditions.

Investigating the effect of anti-CD40L antibody treatment showed that the absence of GC B cells 5 weeks after the initial injection correlated with a decrease in IgG2b/c-expressing GC B cells (Fig. 5g,h). Moreover, at this time point, serum IgG2b and IgG2c ANA levels were also reduced in $S L C^{-/-}$mice treated with anti-CD40L antibodies as compared with prior treatment or isotype-treated controls (Fig. 5i). Thus, ANA production in $S L C^{-1-}$ mice is $\mathrm{Td}$, and suggests that the GC B cells give rise to short-lived plasma cells producing the IgG2b and IgG2c ANAs.

Development of $\mathrm{CD}^{+}{ }^{+} \mathrm{PD}-\mathrm{L2}^{+} \mathrm{CD}^{+} 3^{+}$memory B cells. Although the GC B cells gave rise to plasma cells, it was unclear whether they would give rise to memory $\mathrm{B}$ cells, which can be defined as $\mathrm{CD} 80^{+} \mathrm{PD}-\mathrm{L} 2{ }^{+} \mathrm{CD} 3^{+}{ }^{+}$cells ${ }^{46}$. We could detect a $\mathrm{CD} 80^{+} \mathrm{PD}-\mathrm{L} 2{ }^{+}$subset among the splenic B cells in $\mathrm{SLC}^{-/-}$ mice but not in control mice (Fig. 6a). These cells also expressed $\mathrm{CD}^{+}{ }^{+}$, whereas the $\mathrm{CD} 80^{-} \mathrm{PD}-\mathrm{L2}^{-}$cells did not, which is consistent with memory and naive $\mathrm{B}$ cells, respectively. Moreover, $\sim 70 \%$ of the $\mathrm{CD} 80^{+} \mathrm{PD}-\mathrm{L} 2{ }^{+} \mathrm{CD} 3^{+}$cells expressed $\mathrm{IgM}$ (Fig. 6b).

To ensure that the $\mathrm{CD} 80^{+} \mathrm{PD}-\mathrm{L} 2{ }^{+} \mathrm{CD}_{73}{ }^{+}$population represented memory B cells, the expressed antibody $V_{H}$ genes were analysed for signs of somatic hypermutation (SHM). By contrast to the naive $\mathrm{B}$ cells $\left(\mathrm{CD} 80^{-} \mathrm{PDL} 2^{-} \mathrm{CD} 73^{-}\right)$, where very few sequences were mutated and with $<1$ mutation per $V_{H}$, $\sim 60 \%$ and $95 \%$ of sequences from the IgM- and IgG-expressing GC B cells were mutated with a mean of 3 and 10 mutations per $V_{H}$, respectively (Fig. 6c). In the IgM- and IgG-expressing $\mathrm{CD} 80^{+} \mathrm{PD}-\mathrm{L} 2{ }^{+} \mathrm{CD}_{3}{ }^{+}$population, $\sim 70 \%$ and $55 \%$ of sequences were mutated, with a mean of five and three mutations per $V_{H}$, respectively. Thus, the BCRs expressed by the GC B cells and the $\mathrm{CD} 80^{+} \mathrm{PD}-\mathrm{L} 2{ }^{+} \mathrm{CD} 73^{+}$cells in $\mathrm{SLC}{ }^{-1-}$ mice have undergone SHM, corroborating that the latter are indeed memory $\mathrm{B}$ cells.

A molecular basis for the spontaneous formation of GCs in SLC ${ }^{-1-}$ mice. By analogy to typical $\mathrm{Td}$ immune responses, it would appear that the GC B cells in SLC ${ }^{-1-}$ mice also derived from FO B cells. However, as the GCs in $S L C^{-/-}$mice developed spontaneously, the actual antigen(s) that initiated and was driving the response is unknown. Owing to the enrichment of FO B cells that expressed $\mu \mathrm{H}$ chains with a prototypic ANA H-CDR3 (Fig. 1a), and our observation that the GC B cells gave rise to short-lived plasma cells secreting IgG ANAs (Fig. 5i), this indicated ANA H-CDR3 as a potential link between the two. Investigating the $\mathrm{H}$ chains expressed by GC B cells, we found that those expressing IgM were indeed enriched for $\mu \mathrm{H}$ chains with prototypic ANA H-CDR3 sequences as compared with those of the naive B-cell population $\left(P<0.001 ; \chi^{2}\right.$-test $)$, in fact, both those with 1 and $\geq 2$ arginine and/or lysine (Fig. 6d). Thus, this provides a molecular basis for the spontaneous formation of the GCs in $S L C^{-/-}$mice.

Selection thresholds based on a prototypic ANA H-CDR3. Considering that a prototypic ANA H-CDR3 was an advantage among IgM-expressing GC B cells, we investigated whether we could see signs of selection in the GCs. We observed a reduction in proportions with a prototypic ANA H-CDR3 among GC B cells expressing $\operatorname{IgG}\left(P<0.001 ; \chi^{2}\right.$-test $)$, and an additional reduction was evident among both the IgM- and IgG-expressing memory B-cell populations $\left(P<0.001 ; \chi^{2}\right.$-test; Fig. $\left.6 \mathrm{~d}\right)$. However, the pattern in IgG-expressing splenic and bone marrow plasma cells was more alike the $\operatorname{IgG}^{+}$GC B cells, albeit with significant differences $\left(P<0.001 ; \chi^{2}\right.$-test; Fig. 6e, and Supplementary Figs 9a,b and 10a). Thus, this showed that in $S L C^{-/-}$mice, cells expressing a $\mathrm{H}$ chain with a prototypic ANA $\mathrm{H}-\mathrm{CDR} 3$ had an advantage in order to enter but not to exit the GC compartment, and suggested different selection thresholds to enter the memory B-cell and plasma cell pools.

Clonal selection based on H-CDR3. To further investigate the selection in the GCs, the H-CDR3 sequences were analysed for length and identity. In the naive B cells from $S L C^{-/-}$mice, the $\mathrm{H}$-CDR3 sequences showed a length distribution that appeared normal with an average of 12 aa residues and, as may be expected of naive B cells, the vast majority was different (Fig. 6f), demonstrating a polyclonal repertoire. The pattern in $\operatorname{IgM}^{+} \mathrm{GC}$ B cells was very different, and although the lengths of the $\mathrm{H}-\mathrm{CDR} 3$ varied also in this population, some were more frequent, for example, those with 11 and 12 aa residues. Moreover, the vast majority of $\mathrm{H}-\mathrm{CDR} 3$ sequences of a particular length, for example, 11 aa residues, was identical. This was also evident in the IgG-expressing GC B and spleen plasma cells, although clones with a shorter $\mathrm{H}$-CDR3, for example, 7 aa residues, were more frequent (Fig. 6f,g). This became even more evident in the memory B-cell populations, with a dominance of either 6 and 12 or 6 and 14 aa residues in length in the $\mathrm{IgM}^{+}$and $\mathrm{IgG}^{+}$memory populations, respectively. Thus, this suggests that in $S L C^{-/-}$ mice, the H-CDR3 sequence is critical in GC selection, with the strongest selection pressure on GC B cells that enter the memory B-cell pools.

Exclusion of $V_{H} 81 X$ from the memory B-cell and plasma cell pools. During our sequence analyses, we noticed that $V_{H} 81 X$ $\left(V_{H} 5-2\right)$ usage was sequentially enriched from $\sim 0.5 \%$ among the naive $\mathrm{B}$ cells to $2 \%$ in the $\mathrm{IgM}^{+}$and $15 \%$ in the IgG ${ }^{+} \mathrm{GC}$ B-cell pools from $S L C^{-/-}$mice $\left(P<0.001 ; \chi^{2}\right.$-test; Fig. $\left.7 \mathrm{a}\right) . V_{H} 81 X$ is one of the most well-studied mouse $V_{H}$ genes, as it is intrinsically self-reactive, overrepresented early in ontogeny and found in natural autoantibodies, as well as in mouse lupus models ${ }^{21,47-49}$. In adult mice, $V_{H} 81 X$ usage is high in pro-B but low in naive $\mathrm{B}$ cells $^{50}$, and as it was low also in the naive B cells from $S L C^{-/-}$ mice, we were surprised by its enrichment among the GC B cells. Analysing the $V_{H} 81 X$ sequences showed a sequential enrichment for $J_{H} 3$, from $\sim 30 \%$ in the naive to $80 \%$ in the $\mathrm{IgG}^{+}$ GC B cells (Fig. 7b), and a sequential reduction in $\mathrm{H}-\mathrm{CDR} 3$ length from 12 to 8 aa residues in the $\mathrm{IgG}^{+} \mathrm{GC} B$ cells (Fig. 7c), consistent with clonal selection. Moreover, the proportion of $V_{H} 81 X$ sequences with a prototypic $\mathrm{H}-\mathrm{CDR} 3$ followed a pattern 
a

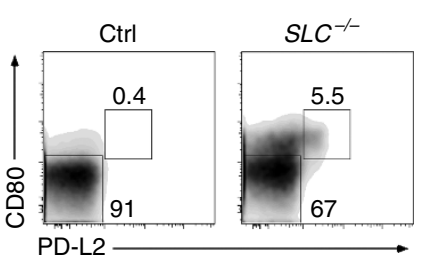

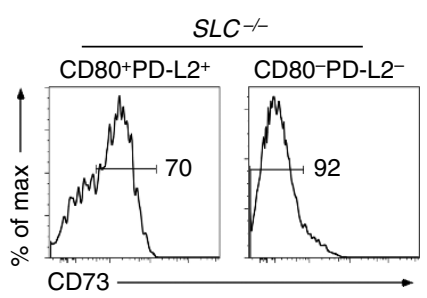

b

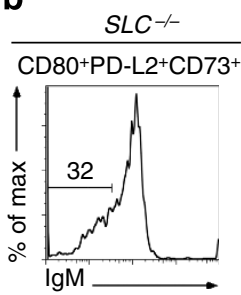

c
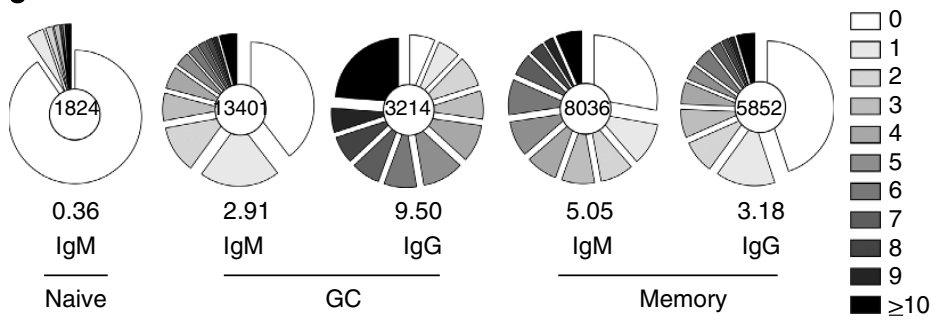

d
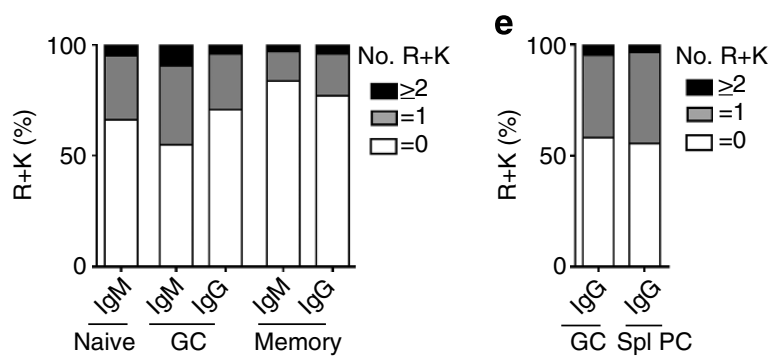

f
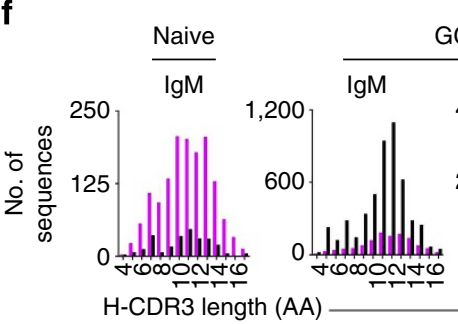

GC

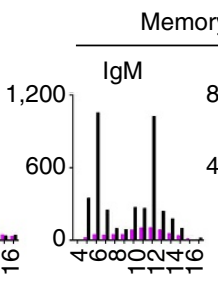

Memory

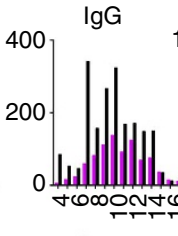

Unique $\mathrm{H}-\mathrm{CDR} 3$
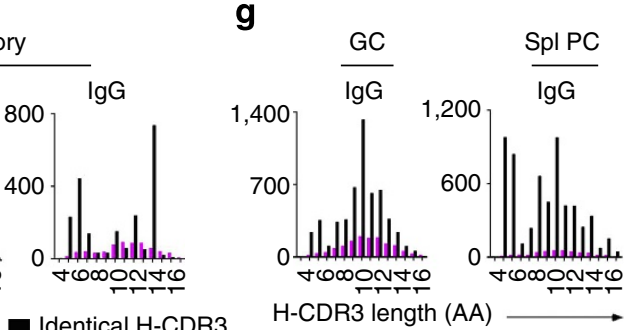

Figure 6 | Selection thresholds based on a prototypic ANA H-CDR3. (a,b) Flow cytometry analysis of spleen cells. (a) Plots show surface expression of

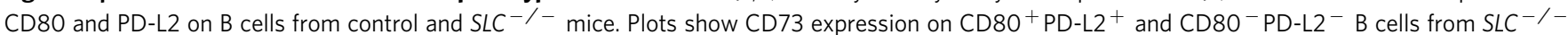
mice. (b) Histogram shows IgM expression on $\mathrm{CD} 80^{+} \mathrm{PD}-\mathrm{L} 2^{+} \mathrm{CD} 73^{+} \mathrm{B}$ cells, bar indicates $\%$ IgM- cells. (c) Analysis of expressed $V_{H} \mathrm{DJ}$ sequences in sorted naive, GC and memory B cells. Pie charts show the proportions of $V_{H}$ sequences that carry $1,2,3$ and so on point mutations in indicated cell populations. Below is shown the average number of mutations per $V_{H}$. (d,e) Proportions of H-CDR3 sequences with 0,1 or $\geq 2$ arginine $(R)$ and/or lysine $(\mathrm{K})$ residues in indicated cell populations. $(\mathbf{f}, \mathbf{g}) \mathrm{H}-\mathrm{CDR} 3$ length distribution in indicated cell populations, with unique and identical sequences, pink and black bars, respectively. Data are representative from at least two independent experiments $(\mathbf{a}, \mathbf{b})$. Data are from a pool of six $(\mathbf{c}, \mathbf{d}, \mathbf{f})$ and five $(\mathbf{e}, \mathbf{g}) S L C^{-/-}$mice. The number of sequences analysed are at the pie chart centre.

similar to that of the entire $V_{H}$ repertoire with an enrichment among the $\mathrm{IgM}^{+}$and reduction among the $\mathrm{IgG}^{+} \mathrm{GC}$ B cells (Figs $7 \mathrm{~d}$ and $6 \mathrm{~d}$ ).

By contrast to the GC B cells, those expressing $V_{H} 81 X$ were in principal excluded (1\%) from both the $\mathrm{IgM}^{+}$and $\operatorname{IgG}^{+}$memory pools (Fig. 7a). Analysing those that did enter, based on $J_{H} 3$ usage and $\mathrm{H}$-CDR3 length, the $V_{H} 81 X$-expressing $\mathrm{IgG}^{+}$memory B cells clearly originated from the $\mathrm{IgG}^{+} \mathrm{GC}$ B cells, whereas the $\mathrm{IgM}^{+}$memory cells were reminiscent of the naive $\mathrm{B}$ cells (Fig. $7 \mathrm{~b}, \mathrm{c})$. Further, $V_{H} 81 X$ sequences with a prototypic ANA H-CDR3 were almost absent from the memory pools (Fig. 7d). Cells expressing $V_{H} 81 X$ were also excluded from the spleen and BM plasma cell pools (Fig. 7e and Supplementary Fig. 10b), and among the few $V_{H} 81 X$-expressing plasma cells a reduction in those with a prototypic ANA H-CDR3 was evident in the spleen (Fig. 7f), but not in the BM (Supplementary Fig. 10c).
Nevertheless, a lack of $V_{H} 81 X$-expressing cells in both the memory B-cell and plasma cell pools could potentially be explained by these cells remaining in the GCs, and presumably continue to undergo SHM. However, the $V_{H} 81 X$ sequences in the GC B cells displayed fewer mutations per $V_{H}$ sequence than those in the entire $V_{H}$ repertoire (Figs $7 \mathrm{~g}$ and $6 \mathrm{c}$ ), observed also in the plasma cell but not IgG memory B-cell pool (Figs $7 \mathrm{~g}$ and $6 c$, and Supplementary Fig. 10d,e). Thus, as most of the cells expressing $V_{H} 81 X$ do not exit the GCs, and as they do not accumulate a large number of mutations, $V_{H} 81 X$-expressing cells seemingly undergo deletion in the GCs. That B cells expressing $V_{H} 81 X$, a BCR with an intrinsically self-reactive $V_{H}$, are expanded in the GCs in $S L C^{-1-}$ mice but excluded from the memory B and plasma cell pools support the hypothesis that peripheral B-cell tolerance in these mice is maintained by selection thresholds on cells entering the memory B-cell and plasma cell pools. 

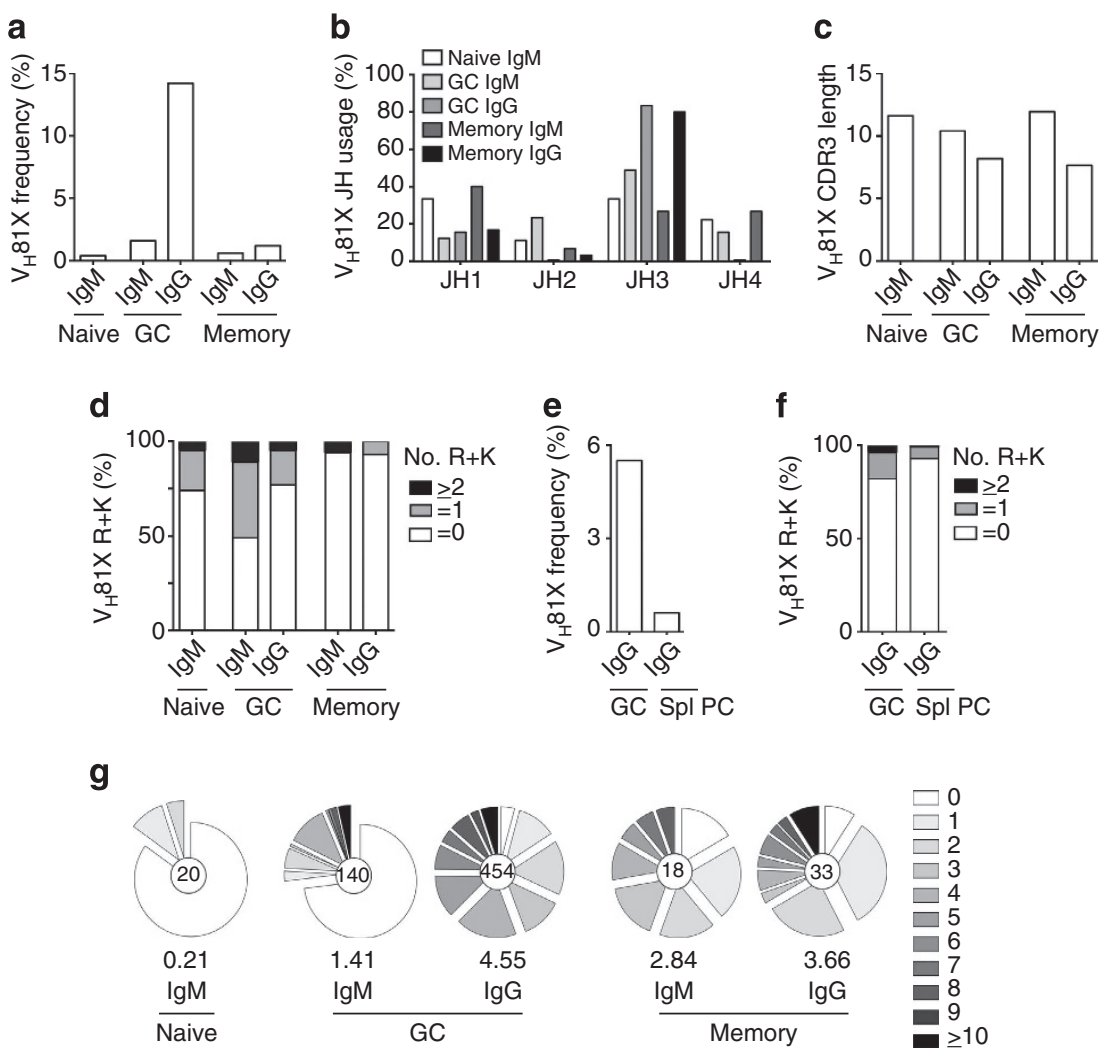

Figure 7 | Expansion of $\boldsymbol{V}_{\boldsymbol{H}} \mathbf{8 1 X}$-expressing $\mathbf{B}$ cells in $\mathbf{G C}$ but exclusion from the memory B-cell and plasma cell pools. (a-g) Analysis of $V_{H} 81 X$ sequences in naive B, GC B-cell, memory B-cell and splenic (Spl) plasma cell (PC) populations in $S L C^{-/-}$mice. (a) $V_{H} 81 X$ usage in indicated cell populations. (b) $J_{H}$ usage and (c) H-CDR3 length in $V_{H} 81 X$ sequences in indicated cell populations. (d) Proportions of $H-C D R 3$ sequences with 0,1 or $\geq 2$ arginine (R) and/or lysine $(K)$ residues in indicated cell populations. (e) $V_{H} 81 X$ usage in indicated cell populations. (f) Proportions of $\mathrm{H}$-CDR3 sequences with 0,1 or $\geq 2$ arginine $(R)$ and/or lysine $(K)$ residues in indicated cell populations. ( $(g)$ Sequence analysis of expressed $V_{H} 81 X$ genes in sorted naive, $G C$ and memory $B$ cells. Pie charts show the proportions of $V_{H} 81 X$ sequences that carry $1,2,3$ and so on point mutations in indicated cell populations. The number below shows the average number of mutations per $V_{H} 81 X$. Data are from a pool of six $(\mathbf{a}-\mathbf{d}, \mathbf{g})$ and five $(\mathbf{e}, \mathbf{f}) S L C^{-} /{ }^{-}$mice. The number of $V_{H} 81 X$ sequences analysed are at the pie chart centre.

\section{Discussion}

The absence of SL chain allows the development of self-reactive naive $\mathrm{B}$ cells, which is sufficient to drive the spontaneous formation of persistent autoreactive Td GCs. Interestingly, peripheral tolerance appears maintained by selection thresholds on the GC B cells entering into the memory B-cell and plasma cell pools. Although some do enter the short-lived plasma cell pool and produce IgG ANAs, those that express seemingly more autoreactive BCRs, for example, the intrinsically self-reactive $V_{H} 81 X$ in combination with an ANA H-CDR3, are excluded. Even though this in itself is not sufficient to tip the balance to overt autoimmunity, it could potentially result in the production of pathogenic autoantibodies.

In current models of B-cell development, some degree of autoreactivity displayed by the pre-BCR appears to be critical for downstream signalling events at the pre-B-cell stage $24-27,51$. This is provided by the $\lambda 5$-tail that interacts with molecules on stromal cells and with neighbouring $\mu \mathrm{H}$ chains ${ }^{24,26,52,53}$. The autoreactivity model is supported by studies in $\lambda 5 \mathrm{~T}$ mice, where expression of a transgenic BCR (3-83) is sufficient to rescue the development of normal B-cell numbers, but only in the presence of autoantigen ${ }^{54}$. Provided that there is a requirement for an autoreactive receptor, pre-BCR or $\mu \mathrm{H}$ chain, this would imply that a majority of pre-B cells in $S L C^{-/-}$mice express a $\mu \mathrm{H}$ chain with some degree of autoreactivity. As we show here, pre-B cells in $S L C^{-/-}$mice are indeed enriched for those that express a prototypic ANA H-CDR3. However, selection at subsequent stages ensures that the proportion of such cells is reduced in the FO B-cell pool. Nevertheless, this pool is still enriched for selfreactivity, which is supported by the spontaneous formation of GCs with an even higher proportion of $\operatorname{IgM}^{+}$B cells that also express $\mu \mathrm{H}$ chains with a prototypic ANA H-CDR3.

In humans, usage of the autoreactive 9G4 idiotype in the naive B-cell pool of SLE patients is not different from that of healthy individuals and RA patients ${ }^{55,56}$. However, owing to its expansion in GCs, and exit into the memory B and long-lived plasma cell pools, 9G4 autoantibodies are abundant in SLE patients, whereas in healthy subjects and RA patients B cells expressing the 9G4 idiotype are not even allowed to enter GCs ${ }^{55}$. Spontaneous formation of Td GCs is observed also in mouse lupus models ${ }^{14}$. Among B-cell hybridomas with anti-DNA/ANA reactivity established from lupus mice, $V_{H} 81 X$ usage is higher than expected $^{21,47}$. It would thus appear that this particular $\mathrm{H}$ chain is undesirable in GCs as well as in the long-lived memory B-cell and plasma cell pools, that is, under conditions where SHMs could give rise to pathogenic autoantibodies. By analogy to $9 \mathrm{G} 4{ }^{+}$ cells, $V_{H} 81 X$ usage in the naive B cells from $S L C^{-/-}$mice is not different from that of controls, and is consistent with observations in $25 T$ mice ${ }^{57}$. However, despite its normal usage in the naive pool, B cells expressing this particular $V_{H}$ enter and expand in the GCs in $S L C^{-}-$mice. By contrast to $9 \mathrm{G} 4$ though, $V_{H} 81 X$ and especially in combination with a prototypic ANA H-CDR3 is, in principal, excluded from both the memory B-cell and plasma cell pools in $S L C^{-/-}$mice. Also GC B cells that express other $V_{H}$ 
genes with a prototypic ANA H-CDR3 follow a similar pattern, although selection on those entering the plasma cell pool is not as strong consistent with the production of IgG2b/c ANAs by short-lived plasma cells. The apparent counter-selection of autoreactivity in the GCs support the hypothesis that peripheral $\mathrm{B}$-cell tolerance in these mice is maintained by different selection thresholds on cells entering the memory B-cell and plasma cell pools.

Analyses of anti-DNA and ANAs from mouse lupus models and SLE patients have shown that they are clonally related and have undergone SHM, hence derive from a typical Td GC response $^{15,21,55}$. It has also been found that reverting these mutations to the germline sequence abolishes antigen binding ${ }^{10,15,58}$, which has led to a model where de novo mutations in GCs give rise to autoreactivity. Under normal circumstances, autoreactive B cells would undergo deletion, whereas in disease situations failure to induce tolerance in GCs would allow such cells to survive. Indeed, de novo mutations in GCs can lead to high-affinity autoantibody production, provided the antigen is not present in the GCs ${ }^{10}$. However, this does not exclude that naive $B$ cells expressing self-reactive BCRs, for example, 9G4 in SLE or those described in RA patients ${ }^{1,2,55}$, act as initiators of GC formation, by analogy to, for example, $V_{H} 81 X$, as we show here.

It has been shown that, for example, viruses can induce autoantibody production ${ }^{59}$, and although a germ-free environment does not affect disease severity in a lupus model, a change in diet results in a milder disease ${ }^{35}$. As the antigen(s) that initially activates the naive $\mathrm{B}$ cells in $S L C^{-/-}$mice is unknown, it could be self-antigen, although we cannot exclude that it is an antigen not depleted by the antibiotics treatment, for example, food antigens, viruses or remaining microbes.

A mutant Roquin protein causes dysregulation of $\mathrm{T}_{\mathrm{FH}}$ cells resulting in excessive numbers of GCs and disease ${ }^{60}$. It has also been proposed that there is a link between overstimulation of $\mathrm{T}_{\mathrm{FH}}$ cells and the development of dysregulated antibody responses ${ }^{61}$. In the SRBC-immunized mice and mouse models of autoimmune diseases, $\mathrm{T}_{\mathrm{FH}}$ cells are found in limiting numbers in the GCs ${ }^{14}$, whereas in the GCs in the $S L C^{-/-}$mice there is an excess of $\mathrm{T}_{\mathrm{FH}}$ cells. In the latter, B-cell proliferation and survival are also different, and perhaps this 'excess' of $\mathrm{T}_{\mathrm{FH}}$ cells is a means to ensure that the $\mathrm{B}$ cells exiting the GCs do not express high-affinity autoantibodies.

Most autoimmune diseases are multigenic, suggesting that multiple mutations, inherited and somatic, are required for disease development. This is also consistent with the detection of autoantibodies long before disease onset in, for example, RA and SLE patients ${ }^{6,7}$, implicating the development of self-reactive naive $\mathrm{B}$ cells as a predisposing factor. However, to tip the balance to manifest disease, which may take years or decades, additional factors would be required, either genetic and/or, for example, immunological triggers. A number of genes and loci have been associated with these diseases affecting, for example, (1) B-cell signalling pathways, (2) phagocytosis of apoptotic cells and (3) the interferon and TLR pathways ${ }^{62}$. Hence, the $S L C^{-/-}$mouse can serve as a model in which to explore the effect of additional factors. Although it is not known whether a dysfunctional SL chain predisposes to autoimmune disease, copy number variation in VPREB1 has been associated with clinical parameters in RA patients ${ }^{63}$.

\section{Methods}

Mice. The $S L C^{-/-}$mice ${ }^{64}$, previously backcrossed for $\geq 10$ generations on the C57BL/6OlaHsd background, were after embryo transfer bred onto the C57BL/ $6 \mathrm{NCrl}$ background and then intercrossed to establish $S L C^{-/-}$mice. Mice were kept in the Gothenburg University specific pathogen free animal facility under project licence authorization (245-2009, 330-2012 and 39-2010) approved by the local ethics committee, and experiments were performed in compliance with ethical regulations. Mice were genotyped by PCR for targeting of VpreB2 and VpreB1/25 (ref. 64). Control mice (C57BL/6NCrl) were purchased from Charles River Laboratories(Germany) and Taconic (Denmark). Female mice were used throughout, aged 1-11 months.

Flow cytometry. Single-cell suspensions were stained with a cocktail of monoclonal antibodies, (Supplementary Table 4) following standard techniques, and permeabilization buffers according to manufacturer's instructions, and were analysed on FACSCantoII, FACSVerse (BD Biosciences) or Synergy (Sony Biotechnology) flow cytometers. Data were analysed using FlowJo software (Treestar Inc.). Owing to the high proportion of $\mathrm{B} 1 \mathrm{~B}$ cells among the $\mathrm{CD} 21^{-} 23^{-}$ population on the C57BL/6NCrl compared with the C57BL/6OlaHsd background ${ }^{28}$, these $\left(\mathrm{CD} 43^{+}\right)$were excluded in the analysis.

Cell sorting. BM and spleen cells were collected and enriched for B cells using CD19 MACS beads (Miltenyi Biotec), followed by sorting pro-B $\left(\mathrm{B}_{2} 20^{+} \mathrm{c}-\mathrm{kit}^{+}\right)$,

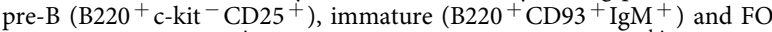
$\left(\mathrm{B} 220^{+} \mathrm{CD} 93^{-} 43^{-} 21^{\text {int }} 23^{+}\right) \mathrm{B}$ cells. $\mathrm{T}_{\mathrm{FH}}$ cells $\left(\mathrm{CD} 4^{+} \mathrm{PD}-1^{\text {hi }}\right)$ and naive $\mathrm{CD} 4^{+}$ $\mathrm{T}$ cells $\left(\mathrm{CD} 4^{+} \mathrm{PD}^{-} 1^{-}\right)$were sorted from individual $\mathrm{SLC}^{-/-}$mice. Sort 1 (Figs 6 and 7): spleen cells were collected from $S L C^{-/-}$mice followed by sorting GC $\left(\mathrm{B} 220^{+} \mathrm{GL} 7{ }^{+} \mathrm{CD}^{+} 5^{+}\right)$, naive $\left(\mathrm{B} 220^{+} \mathrm{CD}^{-} 3^{-} 43^{-} 80^{-} \mathrm{PD}-\mathrm{L} 2^{-} 73^{-}\right)$and memory (B220 ${ }^{+} \mathrm{CD} 3^{-} 43^{-} 80^{+}$PD-L2 ${ }^{+} 73^{+}$) B cells. Sort 2 (Figs 6 and 7 , and Supplementary Fig. 9): spleen GC B and plasma cells, and BM plasma cells were sorted from a pool of five $S L C^{-/-}$mice. GC B and plasma cells were obtained by enrichment-sort for $\mathrm{CD} 19^{+} \mathrm{CD}^{-} 3^{-}$and $\mathrm{CD} 19^{\text {low } /+} \mathrm{CD} 93^{\text {hi }}$ cells, followed by purity-sort for $\mathrm{GC} \mathrm{B}\left(\mathrm{CD} 19^{+} \mathrm{CD} 95^{+} \mathrm{GL}^{+}\right)$and plasma (CD19low/ $\left.+\mathrm{CD} 93^{\text {hi }}\right)$ cells. BM plasma cells were obtained by enrichment-sort for B220 ${ }^{-} \mathrm{CD} 138^{\mathrm{hi}}$ cells, followed by purity-sort using the same markers (Supplementary Fig. 9). Cells were sorted on a FACSAria (BD Biosciences) or Synergy cell sorter (Sony Biotechnology) with purities $>90 \%$.

Immunohistochemistry. Spleens of $S L C^{-/-}$and control mice were collected and embedded in OCT compound (TissueTek, Tokyo, Japan), snap-frozen in liquid nitrogen and stored at $-80^{\circ} \mathrm{C}$. Intestine was collected from $S L C^{-/-}$mice that had undergone antibiotics treatment. Frozen sections $(8 \mu \mathrm{m})$ were cut using a cryostat Leica, (Wetzlar, Germany) and stained (Supplementary Table 4). For intracellular staining of Bcl-6 and Ki-67, the sections were permeabilized using PBS with $0.1 \%$ saponin before blocking with normal horse serum. Subsequently, the sections were stained for 30-60 min at room temperature with primary antibody except for Bcl-6, which was stained overnight at $4{ }^{\circ} \mathrm{C}$. Images were acquired using LSM 700 confocal microscope and ZEN 2009 acquisition software (Zeiss).

Reverse transcription and qPCR. RNA was isolated using RNeasy kit (Qiagen) and cDNA was reversely transcribed using SuperScript II (Invitrogen). Aicda was quantified by qPCR and normalized to the expression of Gapdh (Applied Biosystems), and cDNA from Peyer's patches was used as positive control. Primer sequences are described in Supplementary Table 5, and Power SYBR Green was used (Applied Biosystems). For gene profiling of FO B cells, the cDNA was applied to TaqMan RT-PCR Mouse Immune Array microfluidic cards (47365297; Applied Biosystems) and data were analysed as described in the manufacturer's protocol. All samples were run in triplicates on a ViiA7 system and analysed with the ViiA7 basic software (Applied Biosystems).

Immunizations. SRBCs in sterile Alsever's solution were purchased from the National Veterinary Institute (HåtunaLab, Bro, Sweden) and stored at $4{ }^{\circ} \mathrm{C}$. SRBCs were washed in PBS three times before immunizing control mice with $5 \times 10^{8}$ cells in $0.2 \mathrm{ml} \mathrm{PBS}$ in the tail vein ${ }^{65}$

Antibiotic treatment. Three- to four-week-old $S L C^{-/-}$mice were treated with broad-spectrum antibiotics in drinking water over 4 weeks starting at the day of weaning. Antibiotics: vancomycin $\left(500 \mathrm{mgl}^{-1}\right)$, nebcina $\left(30 \mathrm{mgl}^{-1}\right)$, metronidazole $\left(1 \mathrm{gl}^{-1}\right)$ dissolved in $\mathrm{NaCl}$ and ampicillin $\left(1 \mathrm{gl}^{-1}\right)$. Sucrose and $0.2 \% \mathrm{NaCl}$ (because of the metronidazole) was added to the water.

Anti-CD40L treatment. $S L C^{-/-}$mice were treated at days 0,2 and 4 with antiCD40L or control hamster Ig (BioXCell), $250 \mu \mathrm{g}$ per injection intravenously. Mice were either killed on day 6 or treated with an additional injection of $500 \mu \mathrm{g}$ on day 11 and then killed 5 weeks post the first injection.

HEp2-assay. Serum ANAs were detected using HEp2 cell-coated slides (Bio-Rad Laboratories) ${ }^{28}$. Serum was diluted 1:40 or serially diluted (Fig. $5 i$ ) before incubating on the slides for $30 \mathrm{~min}$ at RT, then washed in PBS and visualized with Alexa Fluor 488-conjugated goat anti-mouse IgG2b (Invitrogen) or IgG2c antibodies (Jackson ImmunoResearch). Sera from a pool of age-matched C57BL/ 
$6 \mathrm{NCrl}$ mice were used as negative control. Confocal fluorescence images were captured with a LSM 700 confocal microscope and ZEN 2009 acquisition software (Zeiss). Two independent observers assessed the intensity of the staining.

Apoptosis assay. After surface staining, apoptotic cells were detected by incubation with zVAD-FMK-FITC (CaspGlow, eBioscience) in RPMI 1640 for $1 \mathrm{~h}$ at $37^{\circ} \mathrm{C}$, according to manufacturer's protocol and then analysed by flow cytometer.

High-throughput sequencing of Ig genes. RNA was isolated using RNeasy kit (Qiagen) and cDNA synthesis was performed according to the SuperScript II RT protocol (Invitrogen). The forward MsVHE primer, representing a consensus sequence of highly conserved codons at the beginning of FWR1, was combined with reverse primers ${ }^{66}$ (Supplementary Table 5), amplifying Ig $\mu$ and Ig $\gamma$ transcripts independently with 10 base multiplex identifier tails. To produce sufficient amounts of DNA for sequencing, while minimizing PCR amplification, 30 cycles were performed using Phusion High-Fidelity DNA Polymerase (NEB). PCR products were purified using QIAquick Gel Purification Kit. Purified samples were mixed in equal quantities for sequencing on the GS FLX + Titanium or GS Junior + sequencer at Eurofins MWG Operon (Germany). Sequences were assigned to the corresponding samples based on the multiplex identifier tags. After passing the quality control criteria, sequences were submitted to IGMT/HighVQUEST database for analysis ${ }^{67}$. The files from IMGT/highV-QUEST were imported into IgAT immunoglobulin analysis tool for further analysis ${ }^{68}$.

Statistics. Mean values and s.e.m. are displayed in the plots. $P$ values were calculated using appropriate statistical test: paired and unpaired $t$-test (GraphPad Prism), or $\chi^{2}$-test (SPSS). ${ }^{\star} P<0.05,{ }^{* *} P<0.01,{ }^{* * *} P<0.001$.

\section{References}

1. Meffre, E. \& Wardemann, H. B-cell tolerance checkpoints in health and autoimmunity. Curr. Opin. Immunol. 20, 632-638 (2008).

2. Yurasov, S. \& Nussenzweig, M. C. Regulation of autoreactive antibodies. Curr. Opin. Rheumatol. 19, 421-426 (2007).

3. Panigrahi, A. K. et al. RS rearrangement frequency as a marker of receptor editing in lupus and type 1 diabetes. J. Exp. Med. 205, 2985-2994 (2008).

4. Kotzin, B. L. Systemic lupus erythematosus. Cell 85, 303-306 (1996).

5. Zvaifler, N. J. The immunopathology of joint inflammation in rheumatoid arthritis. Adv. Immunol. 16, 265-336 (1973).

6. Arbuckle, M. R. et al. Development of autoantibodies before the clinical onset of systemic lupus erythematosus. N. Engl. J. Med. 349, 1526-1533 (2003).

7. Rantapaa-Dahlqvist, S. What happens before the onset of rheumatoid arthritis? Curr. Opin. Rheumatol. 21, 272-278 (2009)

8. Goodnow, C. C., Sprent, J., Fazekas de St Groth, B. \& Vinuesa, C. G. Cellular and genetic mechanisms of self tolerance and autoimmunity. Nature 435, 590-597 (2005).

9. Tarlinton, D. \& Good-Jacobson, K. Diversity among memory B cells: origin, consequences, and utility. Science 341, 1205-1211 (2013).

10. Brink, R. The imperfect control of self-reactive germinal center B cells. Curr. Opin. Immunol. 28, 97-101 (2014).

11. Shlomchik, M. J. Sites and stages of autoreactive B cell activation and regulation. Immunity 28, 18-28 (2008).

12. Victora, G. D. \& Nussenzweig, M. C. Germinal centers. Annu. Rev. Immunol. 30, 429-457 (2011).

13. Dorner, T., Giesecke, C. \& Lipsky, P. E. Mechanisms of B cell autoimmunity in SLE. Arthritis Res. Ther. 13, 243 (2011).

14. Luzina, I. G. et al. Spontaneous formation of germinal centers in autoimmune mice. J. Leukoc. Biol. 70, 578-584 (2001).

15. Schroeder, K., Herrmann, M. \& Winkler, T. H. The role of somatic hypermutation in the generation of pathogenic antibodies in SLE. Autoimmunity 46, 121-127 (2013).

16. Conley, M. E. \& Burrows, P. D. Plugging the leaky pre-B cell receptor. J. Immunol. 184, 1127-1129 (2010).

17. Melchers, F. The pre-B-cell receptor: selector of fitting immunoglobulin heavy chains for the B-cell repertoire. Nat. Rev. Immunol. 5, 578-584 (2005).

18. Xu, J. L. \& Davis, M. M. Diversity in the CDR3 region of $\mathrm{V}(\mathrm{H})$ is sufficient for most antibody specificities. Immunity 13, 37-45 (2000).

19. Vale, A. M. et al. The link between antibodies to OxLDL and natural protection against pneumococci depends on DH gene conservation. J. Exp. Med. 210, 875-890 (2013).

20. Winkler, T. H., Fehr, H. \& Kalden, J. R. Analysis of immunoglobulin variable region genes from human IgG anti-DNA hybridomas. Eur. J. Immunol. 22, 1719-1728 (1992).

21. Radic, M. Z. \& Weigert, M. Genetic and structural evidence for antigen selection of anti-DNA antibodies. Annu. Rev. Immunol. 12, 487-520 (1994).

22. Eilat, D. \& Naparstek, Y. Anti-DNA autoantibodies: a puzzle of autoimmune phenomena. Immunol. Today 20, 339-342 (1999).
23. Marion, T. N., Tillman, D. M., Jou, N. T. \& Hill, R. J. Selection of immunoglobulin variable regions in autoimmunity to DNA. Immunol. Rev. 128, 123-149 (1992).

24. Herzog, S. \& Jumaa, H. Self-recognition and clonal selection: autoreactivity drives the generation of B cells. Curr. Opin. Immunol. 24, 166-172 (2012).

25. Tussiwand, R., Bosco, N., Ceredig, R. \& Rolink, A. G. Tolerance checkpoints in B-cell development: Johnny B good. Eur. J. Immunol. 39, 2317-2324 (2009).

26. Vettermann, C. \& Jack, H. M. The pre-B cell receptor: turning autoreactivity into self-defense. Trends Immunol. 31, 176-183 (2010).

27. von Boehmer, H. \& Melchers, F. Checkpoints in lymphocyte development and autoimmune disease. Nat. Immunol. 11, 14-20 (2010).

28. Keenan, R. A. et al. Censoring of autoreactive B cell development by the pre-B cell receptor. Science 321, 696-699 (2008).

29. Minegishi, Y. \& Conley, M. E. Negative selection at the pre-BCR checkpoint elicited by human mu heavy chains with unusual CDR3 regions. Immunity 14, 631-641 (2001).

30. Ren, W. et al. Surrogate light chain is required for central and peripheral B-cell tolerance and inhibits anti-DNA antibody production by marginal zone B cells. Eur. J. Immunol. 45, 1228-1237 (2015).

31. Ma, C. S. et al. Early commitment of naive human CD4 $(+) \mathrm{T}$ cells to the $\mathrm{T}$ follicular helper $(\mathrm{T}(\mathrm{FH}))$ cell lineage is induced by IL-12. Immunol. Cell Biol. 87, 590-600 (2009).

32. Avalos, A. M. et al. Differential cytokine production and bystander activation of autoreactive B cells in response to $\mathrm{CpG}-\mathrm{A}$ and $\mathrm{CpG}-\mathrm{B}$ oligonucleotides. J. Immunol. 183, 6262-6268 (2009).

33. Bourke, E., Bosisio, D., Golay, J., Polentarutti, N. \& Mantovani, A. The toll-like receptor repertoire of human B lymphocytes: inducible and selective expression of TLR9 and TLR10 in normal and transformed cells. Blood 102, 956-963 (2003).

34. Taylor, J. J., Pape, K. A. \& Jenkins, M. K. A germinal center-independent pathway generates unswitched memory B cells early in the primary response. J. Exp. Med. 209, 597-606 (2012).

35. Chervonsky, A. V. Influence of microbial environment on autoimmunity. Nat. Immunol. 11, 28-35 (2010).

36. Fagarasan, S. et al. Critical roles of activation-induced cytidine deaminase in the homeostasis of gut flora. Science 298, 1424-1427 (2002).

37. Crotty, S. Follicular helper CD4 T cells (TFH). Annu. Rev. Immunol. 29, 621-663 (2011).

38. King, C. New insights into the differentiation and function of $\mathrm{T}$ follicular helper cells. Nat. Rev. Immunol. 9, 757-766 (2009).

39. McHeyzer-Williams, M., Okitsu, S., Wang, N. \& McHeyzer-Williams, L. Molecular programming of B cell memory. Nat. Rev. Immunol. 12, 24-34 (2012).

40. Tew, J. G., Kosco, M. H., Burton, G. F. \& Szakal, A. K. Follicular dendritic cells as accessory cells. Immunol. Rev. 117, 185-211 (1990).

41. Wang, X. et al. Follicular dendritic cells help establish follicle identity and promote B cell retention in germinal centers. J. Exp. Med. 208, 2497-2510 (2011).

42. Ueno, H., Banchereau, J. \& Vinuesa, C. G. Pathophysiology of T follicular helper cells in humans and mice. Nat. Immunol. 16, 142-152 (2015).

43. Shulman, Z. et al. T follicular helper cell dynamics in germinal centers. Science 341, 673-677 (2013).

44. Victora, G. D. \& Nussenzweig, M. C. Germinal centers. Annu. Rev. Immunol. 30, 429-457 (2012).

45. Vinuesa, C. G., Linterman, M. A., Goodnow, C. C. \& Randall, K. L. T cells and follicular dendritic cells in germinal center B-cell formation and selection. Immunol. Rev. 237, 72-89 (2010).

46. Tomayko, M. M., Steinel, N. C., Anderson, S. M. \& Shlomchik, M. J. Cutting edge: hierarchy of maturity of murine memory B cell subsets. J. Immunol. 185, 7146-7150 (2010).

47. Bellon, B. et al. High frequency of autoantibodies bearing cross-reactive idiotopes among hybridomas using VH7183 genes prepared from normal and autoimmune murine strains. J. Clin. Invest. 79, 1044-1053 (1987).

48. Chen, X. \& Kearney, J. F. Generation and function of natural self-reactive B lymphocytes. Semin. Immunol. 8, 19-27 (1996).

49. Carlsson, L., Overmo, C. \& Holmberg, D. Developmentally controlled selection of antibody genes: characterization of individual VH7183 genes and evidence for stage-specific somatic diversification. Eur. J. Immunol. 22, 71-78 (1992).

50. Huetz, F., Carlsson, L., Tornberg, U. C. \& Holmberg, D. V-region directed selection in differentiating B lymphocytes. EMBO J. 12, 1819-1826 (1993).

51. Almqvist, N., Winkler, T. H. \& Martensson, I. L. Autoantibodies: focus on antiDNA antibodies. Self Nonself 2, 11-18 (2011).

52. Espeli, M., Mancini, S. J., Breton, C., Poirier, F. \& Schiff, C. Impaired B-cell development at the pre-BII-cell stage in galectin-1-deficient mice due to inefficient pre-BII/stromal cell interactions. Blood 113, 5878-5886 (2009).

53. Ubelhart, R. et al. N-linked glycosylation selectively regulates autonomous precursor BCR function. Nat. Immunol. 11, 759-765 (2010). 
54. Eschbach, C. et al. Efficient generation of B lymphocytes by recognition of selfantigens. Eur. J. Immunol. 41, 2397-2403 (2011).

55. Cappione, 3rd A. et al. Germinal center exclusion of autoreactive B cells is defective in human systemic lupus erythematosus. J. Clin. Invest. 115, 3205-3216 (2005).

56. Richardson, C. et al. Molecular basis of 9G4 B cell autoreactivity in human systemic lupus erythematosus. J. Immunol. 191, 4926-4939 (2013).

57. ten Boekel, E., Melchers, F. \& Rolink, A. G. Changes in the V(H) gene repertoire of developing precursor B lymphocytes in mouse bone marrow mediated by the pre-B cell receptor. Immunity 7, 357-368 (1997).

58. Mietzner, B. et al. Autoreactive IgG memory antibodies in patients with systemic lupus erythematosus arise from nonreactive and polyreactive precursors. Proc. Natl Acad. Sci. USA 105, 9727-9732 (2008).

59. Zinkernagel, R. M. et al. Virus-induced autoantibody response to a transgenic viral antigen. Nature 345, 68-71 (1990).

60. Vinuesa, C. G. et al. A RING-type ubiquitin ligase family member required to repress follicular helper $\mathrm{T}$ cells and autoimmunity. Nature $\mathbf{4 3 5}$, 452-458 (2005).

61. Baumjohann, D. et al. Persistent antigen and germinal center B cells sustain T follicular helper cell responses and phenotype. Immunity 38, 596-605 (2013).

62. Harley, I. T. W., Kaufman, K. M., Langefeld, C. D., Harley, J. B. \& Kelly, J. A. Genetic susceptibility to SLE: new insights from fine mapping and genomewide association studies. Nat. Rev. Genet. 10, 285-290 (2009).

63. Yim, S. H. et al. The potential role of VPREB1 gene copy number variation in susceptibility to rheumatoid arthritis. Mol. Immunol. 48, 1338-1343 (2011).

64. Shimizu, T., Mundt, C., Licence, S., Melchers, F. \& Martensson, I. L. VpreB1/ VpreB2/lambda 5 triple-deficient mice show impaired B cell development but functional allelic exclusion of the IgH locus. J. Immunol. 168, 6286-6293 (2002).

65. Rutemark, C. et al. Requirement for complement in antibody responses is not explained by the classic pathway activator IgM. Proc. Natl Acad. Sci. USA 108, E934-E942 (2011).

66. Tiller, T., Busse, C. E. \& Wardemann, H. Cloning and expression of murine Ig genes from single B cells. J. Immunol. Methods 350, 183-193 (2009).

67. Brochet, X., Lefranc, M. P. \& Giudicelli, V. IMGT/V-QUEST: the highly customized and integrated system for IG and TR standardized V-J and V-D-J sequence analysis. Nucleic Acids Res. 36, W503-W508 (2008).
68. Rogosch, T. et al. Immunoglobulin analysis tool: a novel tool for the analysis of human and mouse heavy and light chain transcripts. Front. Immunol. doi:10.3389/fimmu.2012.00176 (2012).

\section{Acknowledgements}

We thank L. Berqvist for cell sorting, L. Löfbom and T. Eneljung for assistance with injections, Kjell Pettersson, Centre for Applied Biostatistics, for statistical analyses, and funding from the Swedish Cancer Foundation, Swedish Science Research Council, Torsten and Ragnar Söderbergs Stiftelser, AFA Insurances (AFA Insurance is an organization owned by Sweden's labour market parties and supports health research), ALF (Avtalet om läkarutbildning och forskning) the regional agreement on medical training and clinical research between the Western Gotaland county council and the University of Gothenburg, King Gustav V Stiftelse, Stiftelsen Lars Hiertas minne, Lundbergs Stiftelse, Swedish Medical Society, Reumatikerförbundet, Lundgrens Stiftelse, Amlövs Stiftelser, Adlerbertska stiftelsen, The Royal Society of Arts and Sciences in Gothenburg, Sigurd och Elsa Golje's mine and the Sahlgrenska Academy.

\section{Author contributions}

I.-L.M., O.G. and W.R. designed the experiments. A.C., A.I.B., A.S., B.B., D.C., G.P., H.C., N.H., O.G., S.A., U.Y. and W.R. carried out or contributed essential reagents and materials for the experiments. A.DeR., I.G. and S.C. contributed substantially to discussions. I.-L.M., O.G. and W.R. wrote the manuscript with contributions from co-authors.

\section{Additional information}

Accession code. The sequencing data are deposited in NCBI Sequence Read Archive (SRA) under the BioProject PRJNA277306 (accession code: SRP055855).

Supplementary Information accompanies this paper at http://www.nature.com/ naturecommunications

Competing financial interests: The authors declare no competing financial interests.

Reprints and permission information is available online at http://npg.nature.com/ reprintsandpermissions/

How to cite this article: Grimsholm, O. et al. Absence of surrogate light chain results in spontaneous autoreactive germinal centres expanding $V_{H} 81 X$-expressing B cells. Nat. Commun. 6:7077 doi: 10.1038/ncomms8077 (2015). 